\title{
Atendimento educacional em ambiente hospitalar: visão do estudante portador de paralisia cerebral sobre direitos e formação
}

\author{
Jucélia Linhares Granemann de Medeiros ${ }^{1}$ \\ Yara Fonseca de Oliveira e Silva ${ }^{2}$
}

\begin{abstract}
RESUMO
Este artigo é fruto de uma pesquisa realizada em 2020 e que investigou o olhar de cinco estudantes portadores de paralisia cerebral hospitalizados sobre o atendimento educacional que recebiam, os seus direitos, o espaço do hospital e o papel do professor. Para a investigação, optou-se pela abordagem qualitativa, cujos dados foram levantados por meio de entrevistas semiestruturadas e atividades mediadas pela pesquisadora, à luz de documentos legais e estudos sobre o atendimento educacional. Os resultados mostraram que os estudantes reconheciam seus direitos a essa assistência pedagógico-hospitalar, mas acreditavam que esse atendimento precisava ser melhorado. No que diz respeito à atuação do professor, afirmaram que ele tem contribuído para dar continuidade a seus processos de aprendizagem, mas que, via de regra, carecem de formação de qualidade para o atendimento educacional hospitalar.
\end{abstract}

PALAVRAS-CHAVE: Direito à educação hospitalar. Formação docente. Paralisia cerebral.

Educational assistance in a hospital setting: the view of students with cerebral palsy on rights and education

\footnotetext{
${ }^{1}$ Pós-doutora em Educação pela UFES, ES, Brasil. Docente do Programa de Pós-graduação em Ensino de Ciências (PPGENSCIENCIAS/INFI/UFMS/BRASIL). Disciplinas pedagógicas do Instituto Biociências, UFMS, Campo Grande, Brasil, Orcid: https://orcid.org/0000-0002-3470-8723. E-mail: $\underline{\text { linhares.granemann@ ufms.br. }}$

${ }^{2}$ Doutora em Políticas Públicas, Estratégias e Desenvolvimento (UFRJ-RJ-BRASIL). Professora do Programa de PósGraduação Interdisciplinar em Educação, Linguagem e Tecnologia da Universidade Estadual de Goiás - PPGIELT - UEG - GO. Orcid: https://orcid.org/0000-0001-5725-478X. E-mail: yarafonsecas09@gmail.com.
} 


\begin{abstract}
This article is the result of a research carried out in 2020 that investigated the views of five hospitalized students with cerebral palsy, about the educational assistance they received, their rights, the hospital space, and the role of the teacher in training. For the investigation, the qualitative approach was chosen, whose data were collected through semi-structured interviews and activities mediated by the researcher, in the light of legal documents and studies on educational assistance. The results showed that students recognized their rights to this pedagogicalhospital assistance, but believed that this service needed to be improved. Concerning the teacher's performance, they stated that he has contributed to continuing their learning processes, but that, as a rule, they lack quality training for hospital educational service.
\end{abstract}

KEYWORDS: Right to hospital education. Teacher training. Cerebral palsy.

La asistencia educativa en el ámbito hospitalario: la perspectiva de los estudiantes con parálisis cerebral sobre los derechos y la formación

\title{
RESUMEN
}

Este artículo es fruto de una investigación realizada en 2020, que indagó en las opiniones de cinco estudiantes hospitalizados con parálisis cerebral sobre la asistencia educativa que recibieron, sus derechos, el espacio hospitalario y el rol del docente en la formación. Para la investigación se optó por el abordaje cualitativo, cuyos datos fueron recolectados a través de entrevistas semiestructuradas y actividades mediadas por el investigador, a la luz de documentos legales y estudios sobre asistencia educativa. Los resultados mostraron que los estudiantes reconocieron sus derechos a esta asistencia pedagógico-hospitalaria, pero creían que este servicio necesitaba ser mejorado. En cuanto al desempeño del docente, manifestaron que ha contribuido a continuar con sus procesos de aprendizaje, pero que, por regla general, carecen de una formación de calidad para la atención educativa hospitalaria.

PALABRAS CLAVE: Derecho a la educación hospitalaria. Formación de profesores. Parálisis cerebral. 


\section{Introdução}

$\mathrm{O}$ atendimento educacional em ambiente hospitalar representa a continuidade de um serviço responsável pela escolarização do aluno quando em tratamento de saúde. Neste artigo, relata-se a pesquisa, realizada no período de janeiro a março de 2020 por uma de suas autoras, sobre a experiência do atendimento pedagógico-educacional recebido por cinco estudantes portadores de paralisia cerebral ${ }^{3}$ internados em um hospital da cidade Campo Grande, MS. A questão que orientou a investigação foi a seguinte: o que pensam e sentem os estudantes sobre o atendimento educacional hospitalar que recebem no que diz respeito aos seus direitos, ao espaço do hospital e ao papel do professor?

Para fundamentar a investigação, optou-se pela abordagem qualitativa, por auxiliar na compreensão e interpretação dos fenômenos sociais, oportunizando a compreensão das interações realizadas durante a pesquisa. A pesquisa foi desenvolvida em etapas complementares: a primeira teve como ponto de partida a revisão bibliográfica, por ser considerada a fase fundamental para constituir a fundamentação teórica do estudo, enquanto a segunda cuidou da análise documental, por ser também um procedimento importante para reconstruir os marcos regulatórios iniciais da institucionalização do atendimento educacional hospitalar, tais como leis, relatórios e diretrizes normativas nacionais.

Em seguida realizou-se a pesquisa de campo com estudantes com deficiência cerebral que vivenciaram ou ainda vivenciavam experiências sucessivas de hospitalizações e que foram atendidos e/ou conheciam a estrutura do referido atendimento escolar. Dentre 12 estudantes hospitalizados, cinco deles fizeram opção para participar da pesquisa, os selecionados são de ambos os sexos, na faixa etária de 15 a 25 anos, que à época frequentavam escolas regulares e/ou universidades. Os participantes são identificados aqui em uma

\footnotetext{
${ }^{3}$ A Organização Mundial de Saúde (1999) descreve a paralisia cerebral (PC), ou encefalopatia crônica não progressiva da infância, como decorrente de lesão estática, ocorrida no período pré, peri ou pós-natal, e que afeta o sistema nervoso central em fase de maturação estrutural e funcional. O termo PC é abrangente, pois apresenta uma variedade de fatores causadores e descreve a evolução do distúrbio da função motora secundários à patologia não progressiva do cérebro imaturo (HARE; DURHAM; GREEN, 2000).
} 
sequência numérica de 1 a 5 , como forma de preservar suas identidades: Estudante 1, Estudante 2 e assim sucessivamente.

Os objetivos da pesquisa foram explicados aos participantes, ocasião em que também se enfatizou a importância da participação voluntária, destacandose que não haveria nenhuma exposição ou prejuízo aos participantes.

O levantamento dos dados foi feito mediante entrevista semiestruturada, segundo um roteiro prévio. Conforme Lakatos (2003, p. 195), “[...] a entrevista é um encontro entre duas pessoas, com o objetivo de se levantar informações a respeito de determinado assunto, mediante uma conversação de natureza profissional". A realização das entrevistas, autorizadas previamente pelos estudantes e seus familiares, ocorreu em 2020, durante os atendimentos hospitalares, e cada uma delas tiveram duração média de duas horas.

O artigo está organizado em três seções, além desta Introdução e das Considerações Finais. As seções trazem as discussões a partir das entrevistas dos estudantes, com os quais se discutiu inicialmente sobre o entendimento que tinham sobre seu direito de receber atendimento educacional em um hospital. A intenção foi mostrar como esse direito é garantido pela legislação. Em seguida, realizou-se a discussão sobre o espaço e o funcionamento do atendimento hospitalar e, por fim, sobre a assistência prestada pelo professor de modo a refletir sobre o seu papel e sua formação.

\section{0 direito do estudante na legislação}

O Art. 205 Constituição Federal de 1988 (CF/1988) define a educação "[...] como direito de todos e dever do Estado e da família e em colaboração com a sociedade" (BRASIL, 1988), orientação que abre a oportunidade para os alunos hospitalizados também receberem assistência educacional. Estudar não é apenas estar matriculado, mas também oportunidade para o educando estabelecer contato com professores, colegas e conteúdos, ampliando seus conhecimentos, aperfeiçoando-se nas relações sociais, capacitando-se para viver em sociedade e desenvolver a cidadania. 
O início do estudo ocorreu com base no conhecimento do estudante sobre a legislação brasileira, no sentido de ilustrar e conscientizá-lo sobre os seus direitos, pois, se a educação é um direito de todos, faz-se necessário que de fato se efetive, mediante a garantia de que qualquer educando terá acesso ao atendimento educacional especializado. É claro que o atendimento educacional deve, preferencialmente, ser oferecido na rede regular de ensino, mas a CF/1988 não veta que ocorra em outros locais, tal como o hospital.

Dessa forma, a primeira questão da entrevista - "O que sabe sobre seu direito, sobre as leis que amparam sua escolarização"? - visou ampliar a compreensão do estudante que se encontra em período de escolarização, mas passa por tratamento prolongado e/ou de hospitalização, sobre seu direito de continuar seus estudos.

Entre outros documentos legais, constou da entrevista com os estudantes que compuseram o universo da pesquisa a Lei $n^{\circ} .7 .853$, de 24 de outubro de 1989, que dispõe sobre o apoio às pessoas com deficiência, sua integração social e institui, dentre outros, a tutela jurisdicional de interesses coletivos ou difusos dessas pessoas. A referida lei confirma o atendimento em ambiente hospitalar como modalidade de educação inclusiva e legaliza a atuação do professor no local, desde que possua formação adequada para isso.

No decorrer do estudo ficou claro para todos - pesquisadora e estudantes que a criança e o adolescente têm direito à educação, visando seu pleno desenvolvimento e o seu preparo para o exercício da cidadania e sua qualificação para o trabalho. Nessa conjuntura, entendeu-se também que um dos programas suplementares é o atendimento pedagógico hospitalar, tendo em vista que permite a continuidade da educação escolar simultaneamente à assistência à saúde.

$\mathrm{O}$ direito ao atendimento hospitalar continuou como parte da entrevista e teve como base a Resolução MEC/SEESP n. ${ }^{\circ}$ 2, de 11 de setembro de 2001, que determina expressamente a implantação da hospitalização escolarizada, com a “[...] finalidade de atendimento pedagógico aos alunos com necessidades especiais transitórias, com a organização de cursos acadêmicos destinados a atender a essa nova demanda, assim reforçando [...] o direito à saúde" (BRASIL, 2002). Segundo a CF/1988 (Art. 196), deve ser garantido o direito à saúde 
mediante políticas econômicas e sociais que visem o acesso universal e igualitário às ações e serviços, tanto para a sua promoção quanto para a sua proteção e recuperação (BRASIL, 1988). Assim, a qualidade do cuidado à saúde refere-se diretamente a uma concepção ampliada desse atendimento, que deve ser estendido às necessidades de moradia, trabalho e educação, dentre outras, que assumem relevância para compor a atenção integral ao educando.

Também foi analisada com os estudantes a Lei de Diretrizes e Base da Educação n. ${ }^{\circ}$ 9.394/1996, que estabelece as diretrizes e bases da educação nacional (LDBEN/1996), para lembrar que esse documento, em seu Art. 58, define a educação especial como modalidade da Educação Básica que deve ser oferecida aos educandos com necessidades especiais, preferencialmente na rede de ensino regular. $\mathrm{O} \S 1^{\circ}$ da LDBEN/1996 recomenda que a escola regular disponibilize "[...] serviços de apoio especializados “[...] para atender às peculiaridades da clientela de educação especial”. Isso significa dizer que todo esse aparato legal deve ser aplicado, pois reflete de forma positiva para o educando, conforme declarou o Estudante 2:

Hoje, pelo que aprendi, acho que [a presença de] professores no hospital deve ser direito de todos. Não podemos deixar nossos colegas ficarem à margem, separados, sem estudar. É muito importante. Não sei nem o que te dizer. É válido, útil, ajuda muito no desenvolvimento, no aprender.

Sobre o direito à educação, o Estudante 4 afirmou que "[...] os governos têm que aumentar atendimentos e liberar recurso para o atendimento". Isso significa que, mesmo sendo legítimos a estruturação e o oferecimento de atendimentos educacionais em ambientes hospitalares e domiciliares, ainda existe a necessidade de clamar por direitos para que políticas públicas sejam implementadas com mais qualidade.

Nesse panorama, entende-se que ambos os estudantes compreendem seus direitos, mas ao mesmo tempo reconhecem que ainda lhes falta a garantia plena para a sua efetivação. É preciso, portanto, continuar a busca por parcerias entre os hospitais e as secretarias de Educação, Saúde e Assistência Social para garantir ao aluno adoecido um atendimento mais humanizado, consoante o que 
a legislação estabelece. Ou seja, seus estudos não devem sofrer solução de continuidade durante seu tratamento, ainda mais quando se considera que esse afastamento do dia a dia da escola pode ser, por vezes, traumático e dolorido.

\section{Ambiente hospitalar}

O significado do ambiente hospitalar foi outro ponto abordado na entrevista com os estudantes. A segunda questão - "Que lugar é esse que se propõe o atendimento educacional?" -, teve como base a compreensão de que, no processo de hospitalização, existe uma tendência de o estudante afastar-se ou evadir-se da escola quando adoecido e, por isso, não receber esse atendimento.

No intuito de mostrar a cada estudante as possíveis formas de ocorrer esse atendimento, após suas respostas buscou-se dialogar com eles sobre o espaço e as possíveis formas de ocorrer esse atendimento educacional hospitalar, conforme preconizam diferentes autores. A questão também desencadeou explicações, tal como a de que o atendimento escolar em ambiente hospitalar, por doença e/ou qualquer outra necessidade de internação, pode ser em caráter provisório. O mesmo ocorre quando os alunos em estado de doença são atendidos em suas residências.

O interesse que orientou a questão foi o de possibilitar a compreensão do estudante sobre seu direito à assistência educacional quando afastado por motivo de saúde e sobre a transitoriedade desse atendimento. Trata-se, portanto, de um processo alternativo de educação continuada que ultrapassa o contexto formal da escola. Quando realizada de forma multi/inter/transdisciplinar e com características educativas próprias, respeitando o momento de doença, a situação de escolaridade, e também os demais desdobramentos na vida social e familiar do educando atendido, essa assistência mostra-se bastante eficaz.

Nessa perspectiva, o atendimento educacional em ambiente hospitalar ou domiciliar deve ser individualizado, respeitando a identidade de cada criança/jovem, levantando todas as suas dificuldades e respeitando sua 
trajetória e desenvolvimento. Esse atendimento deve ocorrer, portanto, quando o sujeito se encontrar em uma situação diferente daquela em que estão os demais alunos. Para tanto, a escola deve elaborar um programa de educação integrada com as atividades escolares no hospital, o que contribuirá para a diminuição da evasão, da repetência e da defasagem de idade/série de crianças e jovens atendidos em relação a seus colegas.

Para González, E. e González, C. (2007), essa clientela constitui um grupo heterogêneo de alunos com necessidades psicológicas, médicas, sociais e educacionais diferentes daquelas que são vivenciadas por crianças de uma classe do ensino regular. Já Barros (2007) defende que essa modalidade de atendimento não precisa ficar reduzida à utilização de um espaço físico circunscrito. Conforme a autora, pode-se utilizar a biblioteca do hospital, os momentos ociosos do refeitório, as varandas da enfermaria e mesmo os leitos.

Ainda conforme Barros (2007), o que é denominado turma, em uma enfermaria pediátrica, é na verdade um grupo aberto e de estrutura dinâmica, o que permite ao educando atendido entrar e dele sair com relativa frequência. Sua estruturação, portanto, é sempre variável, pois, para cada educando atendido, o tempo de permanência no hospital será diferente e, por conseguinte, também a duração, extensão e natureza do investimento pedagógico/terapêutico recebido (BARROS, 1999). Com relação ao perfil do grupo atendido, verifica-se que esse é também variável, uma vez que os pacientes hospitalizados possuem demandas acadêmicas e origens socioeconômicas diversas.

De acordo com Sandroni (2008), o professor pode atuar não só com atividades relacionadas aos conteúdos escolares, mas também com outras que visem o desenvolvimento psíquico e cognitivo dos enfermos. A vertente lúdica, conforme a autora, também é uma boa opção para o trabalho com crianças e adolescentes hospitalizados, pois instiga a curiosidade, a criatividade e a busca pelo saber. Para ela, isso fica mais visível quando são utilizados recursos eletrônicos, tais como vídeo, CD-ROM, computador e jogos.

Para analisar esse atendimento, importa destacar a advertência feita por Matos e Mugiatti (2009) de que não se pode olhar o paciente apenas pelo 
seu caso físico, e sim levar em consideração os fatores psicossociais por trás da doença. Para as autoras, "[...] trata-se do atendimento a uma pessoa, em todas as suas dimensões, e não, simplesmente, da atenção a uma determinada doença" (p. 20). As autoras pontuam que o estado do paciente muitas vezes é multifatorial, por isso, é necessário compreendê-lo em todos os aspectos. Acrescentam também que as crianças hospitalizadas mais de uma vez se amedrontam com a rotina de um hospital o que pode acarretar dificuldades no processo de ensino e aprendizagem.

Com base nas análises feitas até aqui, é possível entender que esse atendimento é possível de ser realizado desde que se considerem as condições do estudante-paciente e que haja um espaço adaptado para o desenvolvimento do processo de ensino e aprendizagem. Por outro lado, a vivência com esses pacientes-estudantes que participaram da pesquisa permitiu constatar suas inseguranças sobre o que de fato poderia ocorrer com suas vidas sem o aconchego do lar, sentimento que podia ser notado em seus olhos assustados e, sobretudo, por estarem muitas vezes sentindo-se sozinhos, deprimidos por serem obrigados a ficar recolhidos a um ambiente hospitalar.

Exemplo disso é a condição sinalizada pelo Estudante 3 ao destacar que sua entrada no hospital foi bastante dolorosa, pois, além de passar por três cirurgias complexas, precisou permanecer internado por diversos dias, tomando diferentes medicações, algumas delas para aliviar a dor. Durante o tempo em que esteve hospitalizado, ele afirma não ter recebido atendimento educacional e declarou que sentiu muita falta de sua rotina e de estar na escola:

Nesse período que estive no hospital, perdi muito conteúdo, matéria escolar! Aula mesmo! Na época não se falava em atendimento escolar, nem tinha compreensão de tudo isso. Perdi ano letivo vários anos! Sempre que ficava internado, ficava numa ala sem muita cor, não tinha atividade, brincadeiras, brinquedoteca, aula como se tem hoje! Seria muito diferente se tivesse! Vejo como é importante isso. (Estudante 3)

De um modo geral, o fato de estar em um ambiente estranho e submetido a uma rotina árdua de contato com médicos e enfermeiros, sem ter certeza sobre 
seu estado de saúde, mexe com a estrutura psicológica do sujeito adoecido. $\mathrm{Na}$ fala acima do Estudante 3, fica claro que o atendimento educacional teria favorecido em muito sua melhora em diferentes aspectos.

Para o Estudante 4, a assistência educacional aconteceu em diferentes momentos, o que se tornou um ponto positivo em seu processo de aprendizagem:

Quanto ao atendimento escolar, tive enquanto fiz tratamento em São Paulo, foi muito bom! Todo dia, vinha uma professora e trazia atividades para eu fazer. Fazia com ela e com minha mãe, depois que ela ia embora. Eu todo dia tomava banho, tomava minha vitamina de banana e bolachinha e ficava todo disposto, esperando a professora! E uma coisa, viu?, aprendi muito. Quando voltei para o estado, fiquei internado várias vezes, e também tive professora no hospital. Foi bom! Fiz até aniversário lá. Me senti, muito importante. Foi a professora e a equipe do hospital que me incentivaram a continuar meus estudos. (Estudante 4)

Além da aprendizagem, percebem-se na fala do Estudante 4 sentimentos e emoções que promoveram a satisfação de estar no ambiente hospitalar, o que diminuiu seu sofrimento vivido naquele momento da doença.

O direito à educação no espaço hospitalar ainda é motivo de preocupação para alguns alunos, conforme destaca o Estudante 5: “[...] deve ser feito leis. Precisa, sabe, cobrar os governantes, tem que ser algo de verdade, que não acabe, que aconteça..." Sua fala sinaliza, para os gestores que estão à frente da implementação das políticas públicas, a necessidade de um repensar sobre a importância dessa assistência educacional hospitalar, que representa tanto o ato de educar como o de humanizar, promovendo ações que contribuam para ampliar o processo de ensinar e contemplem um atendimento integral, ou seja, de assistência e de cuidado com o outro, com o estudante.

\section{Papel do professor no atendimento hospitalar}

Ceccim (1999) afirma que, para atender o aluno hospitalizado, o professor tem de entender que o seu papel não é apenas o de ocupar criativamente o tempo do educando para que ele possa expressar e elaborar os sentimentos trazidos pelo adoecimento e pela hospitalização, e aprender novas condutas emocionais. 
Ao contrário, conforme o autor, cabe ao docente: abrir espaços lúdicos, com ênfase no lazer pedagógico, para que o aluno esqueça por alguns momentos que está doente ou em um hospital, e operar com os processos afetivos de construção da aprendizagem cognitiva, permitindo aquisições escolares. Ceccim (1999) pontua ainda que o contato do professor com uma "escola no hospital" é uma oportunidade de ligação com os padrões da vida cotidiana do comum das crianças, ou seja, representa um elo com a vida em casa e na escola.

$\mathrm{O}$ atendimento educacional em ambiente hospitalar se apoia, de acordo com Fonseca (1999), em propostas educativo-escolares que se diferenciam das atividades lúdicas e de recreação que porventura existirem na instituição hospitalar. Explica a autora que, mesmo se o lúdico for uma estratégia do aprendizado no ambiente hospitalar, a intervenção pedagógico-educacional é mais específica, por ser individualizada, estar embasada em uma regularidade e ter responsabilidade com o aprendizado formal da criança. $\mathrm{Ou}$ seja, é uma atividade inclusiva dos pais e das escolas de origem da criança, pois receber aulas durante a sua hospitalização, além de servir à manutenção das aprendizagens escolares, é um incentivo ao retorno e à reintegração do educando ao espaço escolar após a alta hospitalar.

Maia-Vasconcelos (2010), afirma que, com o atendimento educacional em ambiente hospitalar, o professor pode compensar as lacunas e devolver ao aluno um pouco de normalidade ao seu modo de vida. Ele pode ser o guardião global do desenvolvimento do educando, respeitando sua doença, sem se esquecer de suas necessidades como pessoa. Outra questão salientada pela autora refere-se à manutenção dos laços afetivos que ajudem o aluno a encontrar o caminho de volta ao seu mundo por meio da linguagem.

Outra recomendação feita por Maia-Vasconcelos (2010) ao professor é a de que ele deve buscar se tornar uma espécie de agência educacional para que o aluno hospitalizado possa desenvolver atividades que o ajudem a construir um percurso cognitivo, emocional e social, a fim de manter uma ligação com sua vida familiar e a realidade no hospital. Destaca, ainda, a necessidade de o docente assegurar o reconhecimento da identidade do educando, fornecendo-lhe um 
percurso cognitivo apropriado à sua idade, para que ele possa compreender a realidade do hospital. Além disso, também deve proporcionar-lhe momentos para jogos e diversões, a fim de assegurar a continuidade educativa com a escola de origem e ajudá-lo e à sua família a empreender novos ritmos e novos projetos, caso o projeto traçado anteriormente tenha se tornado inviável.

Nesse sentido, são diversas as atribuições que competem ao professor de uma classe hospitalar, dentre elas, fazer o diagnóstico das dificuldades específicas no aprendizado do aluno e aplicar estratégias para sanar tais problemas; e elaborar recomendações para os pais seguirem na volta do hospitalizado para a casa e para a escola de origem ao término da internação. Portanto, atuar como professor em classe hospitalar significa, conforme pontuam Zombini et al. (2012), promover o diálogo, explorar o ambiente hospitalar junto com a criança internada, perceber no educando a sua visão de vida, as suas necessidades e seus problemas, para que possa, com base nelas, desenvolver uma prática pedagógica adequada à sua realidade, contribuindo assim para a construção dos conhecimentos necessários para uma ação ativa em prol do restabelecimento de sua saúde.

Sobre o papel do professor, Fontes (2002) afirma ser aquele que promova um elo entre o mundo hospitalar e a vida cotidiana da criança hospitalizada. Para tanto - diz ela -, é necessário que o professor receba capacitação, primeiro, porque essa atividade, ao acionar o lúdico como canal de comunicação com o estudante hospitalizado, procura fazê-lo esquecer, durante alguns instantes, o ambiente agressivo no qual se encontra, resgatando sensações vividas anteriormente à entrada no hospital. Segundo, porque, ao conhecer e desmistificar o ambiente hospitalar, ressignificando suas práticas e rotinas - que é uma das propostas de atendimento pedagógico em hospital -, “[...] o medo que paralisa as ações e cria resistência, tende a desaparecer, surgindo em seu lugar a intimidade com o espaço e a confiança naqueles que cuidam dela" (FONTES, 2004, p. 4).

Para desempenhar bem o seu papel, conforme Ortiz e Freitas (2005, p. 55), o professor deve “[...] implementar a continuidade ao ensino dos conteúdos 
da escolarização regular ou mesmo investir no trabalho escolar com conteúdos programáticos próprios à faixa etária da criança”, pois deve buscar sanar as dificuldades de aprendizagem e propiciar a aquisição de novos saberes. Ainda conforme as autoras, é também papel do professor "[...] promover a apropriação de habilidades e aprendizagens escolares, fortalecendo o retorno e reinserção da criança no contexto do ensino regular", pois, ao disponibilizar a proteção à afetividade como fenômeno garantidor da aceitação e respeito à singularidade do paciente-aluno, é possível fortalecer "[...] a construção subjetiva do viver, respaldada por superação psicológica do adoecimento e fomentar as relações sociais como veículo de instrumentalização do aprendiz". Dessa forma, o professor torna-se um "[...] agente sociointerativista e estimulador do desenvolvimento socioafetivo" (p. 55).

Enfim, vale destacar que, para Sandroni (2008), o professor deve ter sólidos conhecimentos sobre o processo de desenvolvimento humano em cada fase escolar e os respectivos conteúdos de cada nível, além de entender as necessidades especiais e as deficiências sejam elas: visual, auditiva, física, intelectual e/ou múltipla, dos alunos-pacientes e ter sensibilidade para dialogar com hospital e família. Tal afirmação coincide com a visão do Estudante 2, ao afirmar: "O professor, para esse serviço [atendimento pedagógico hospitalar], precisa ter muito conhecimento, boa vontade e amor ao próximo". Assim, o professor responsável pelo atendimento educacional em ambiente hospitalar tem como função manter as atividades escolares durante o período de internação da criança ou do adolescente hospitalizado, mas não deve considerar só o desenvolvimento cognitivo, com as atividades e os conteúdos escolares, mas também o desenvolvimento psíquico e emocional.

Quando sensível às condições de vulnerabilidade e fragilidade dos alunos-pacientes, o professor torna-se um importante elemento para garantir o estabelecimento de uma desejável relação de confiança. Exemplo disso é a seguinte afirmação do Estudante 1: "Tudo que sou devo a eles [professores]. Tive muito professor que nem deu a minima para mim, mas tive também aqueles que me ajudaram. Devo tudo que sou a eles. São meus grandes 
exemplos, minha inspiração". Vê-se nessa fala que a ação do professor propicia condições de bem-estar, pois, ao estimular a autonomia do educando e, principalmente, ao criar um vínculo afetivo com ele, certamente contribuiu para a melhoria das condições de aprendizagem do aluno.

O atendimento educacional em ambiente hospitalar é responsável, portanto, pela sustentação do retorno e da reintegração do aluno ao seu grupo escolar e social, já que ele poderá se sentir excluído de seu meio social devido ao tempo em que precisou ficar afastado. Nesse sentido, ainda que um dos pressupostos do atendimento educacional em ambiente hospitalar seja o estímulo à aquisição de habilidades e competências linguísticas e lógicomatemáticas, o espaço permite ao educador desenvolver outras atividades, dentre as quais aquelas voltadas para a educação em saúde não apenas das crianças e dos adolescentes hospitalizados, mas também de seus familiares. Essa é uma atividade que pode se tornar um elemento motivador para a adoção de atitudes conducentes à saúde. Procura-se assim, superar a lógica da compartimentação dos conhecimentos, tornando possíveis os diversos modos de aprender, de fazer e de saber. (BARROS, 2007).

Desse modo, a permanência do estudante no hospital não deve representar o rompimento de seu vínculo com a escola e a perda do direito à escolarização. $\mathrm{O}$ atendimento educacional em ambiente hospitalar garante às crianças e aos adolescentes hospitalizados a oportunidade de continuarem a vivenciar as experiências pedagógicas. Além de não interromper o contato com o saber, o que estimula os processos cognitivo e de desenvolvimento, também permite a continuidade das relações interpessoais.

Devido ao contato diário com o paciente e seus familiares, o professor da classe hospitalar auxilia nas interações com a equipe de saúde, pois é capaz de identificar, graças à experiência adquirida em sala de aula, padrões de comportamento que porventura não tenham sido percebidos pela equipe. $\mathrm{O}$ professor do atendimento educacional em ambiente hospitalar deve articular-se com a equipe de saúde do hospital, com a Secretaria de Educação e com a escola de origem do educando, colaborando, assim, para a atenção ao restabelecimento 
de sua saúde e garantindo, por meio do cumprimento da matriz curricular, a continuidade do aprendizado e a aprovação da criança ou do adolescente para o próximo ano escolar (ZORBINI et al., 2012).

Ao discutir esse processo, percebe-se que que conforme Ceccim (1999), a oportunidade de frequentar uma classe hospitalar devolve à criança ou ao adolescente o prazer do contato com o ambiente escolar, privilegiando as suas conquistas de aprendizagem e desvinculando-a, ainda que momentaneamente, das restrições que a hospitalização impõe. O resultado dessa atenção é tornar a experiência de hospitalização um acontecimento positivo ao crescimento e desenvolvimento do educando.

Enfim, com a pesquisa realizada com os estudantes hospitalizados, constatou-se que, de uma forma geral, as atribuições do professor para atuar no atendimento educacional em ambiente hospitalar são as de oferecer auxílio emocional e cognitivo para o educando, conclusão a que chegaram também outros pesquisadores. Conforme apreende-se da fala dos estudantes entrevistados, a formação do professor, seja ela inicial ou continuada, é primordial para que ele possa desenvolver com mais qualidade suas atividades. Conforme destaca Caiado (2003), as universidades que possuem compromisso com a realidade social e compreendem a educação e a saúde como direitos sociais não têm problemas com a formação do professor, apreciando os múltiplos espaços e tempos da educação, incluindo-se aí a classe hospitalar.

Diante disso, o papel do professor passa pela sua formação, e a universidade, ao preparar o pedagogo, deve primar por uma formação que possibilite uma prática pedagógica que compreenda o atendimento hospitalar como uma nova alternativa educacional. A formação do professor possibilita um comprometimento político-pedagógico e fortalece sua competência profissional.

\section{Considerações finais}

O estudo aqui apresentado trouxe a discussão sobre o atendimento educacional em ambiente hospitalar, o qual busca propiciar o acompanhamento 
curricular do estudante hospitalizado, para garantir a manutenção de seu vínculo com a escola. Esse processo é um direito do estudante, conforme consta na legislação, mas importa destacar que essa oferta ainda é pequena e que, conforme os estudantes que participaram da pesquisa que embasa este artigo, ainda precisa ser garantida a todos que dela necessitem.

Acerca do atendimento educacional em ambiente hospitalar, percebeuse, com a contribuição dos estudantes, que o hospital tanto pode ser um lugar de desconforto, por causa dos procedimentos médicos, que causam dor e medo, como um ambiente transitório, necessário, que faz parte da vida e que muito contribui para uma formação humana e dialógica com base no desenvolvimento de conhecimentos e habilidades. Essas podem ser compartilhadas com os demais colegas hospitalizados, com a equipe atendente e com os professores do atendimento hospitalar e aqueles lotados em sua escola de origem. Mas, para isso, o espaço a ser implementado precisa estar em condições para a realização das ações necessárias ao atendimento.

O professor, ainda pelo olhar do aluno, tem realizado um papel que contribui para aperfeiçoar o processo de aprendizagem e ampliar a visão de mundo dos educandos. Para isso, faz-se necessário fortalecer o diálogo acerca da necessidade da implementação de políticas públicas mais eficazes para a formação do docente que fará o atendimento educacional hospitalar, e, sobretudo, para que as políticas e legislações vigentes sejam cumpridas. Essa formação acadêmica, principalmente nas diferentes licenciaturas, deve possibilitar uma prática pedagógica que compreenda o atendimento hospitalar como uma nova alternativa educacional e ter em vista que um comprometimento político-pedagógico fortalece a competência profissional.

\section{Referências}

BARROS, A. S. S. A prática pedagógica em uma enfermaria pediátrica: contribuições da classe hospitalar à inclusão desse alunado. Revista Brasileira de Educação, Rio de Janeiro, n. 12, p. 84-93, 1999. 
BARROS, A. S. S. Contribuições da educação profissional em saúde à formação para o trabalho em classes hospitalares. Caderno Cedes, Campinas-SP, v. 27, n. 73 , p. $257-278,2007$.

BRASIL. Constituição (1988). Constituição da República Federativa do Brasil. Brasília, DF: Senado Federal, 1988. Disponível em: $<$ https://www2.senado.leg.br/bdsf/bitstream/handle/id/518231/CF88/>. Acesso em: jul. 2020.

BRASIL. Lei n. 7.583, de 24 de outubro de 1989. Dispõe sobre o apoio às pessoas Portadoras de deficiência, sua integração social, sobre a Coordenadoria Nacional para Integração da Pessoa Portadora de Deficiência. Brasília, DF. Disponível em: $<$ http://www.planalto.gov.br/ccivil_03/leis/L7853.htm>. Acesso em: 19 de Set 2019.

BRASIL. Lei ${ }^{\circ}$. 9.394, de 20 de dezembro de 1996. Estabelece as diretrizes e bases da educação nacional. Diário Oficial da União, Brasília, DF, 23 dez. 1996. Disponível em:

$<$ https://www2.senado.leg.br/bdsf/bitstream/handle/id/70320/65.pdf/>.

Acesso em: jul. 2020.

BRASIL. Conselho Nacional de Educação. Câmara de Educação Básica. Resolução $\mathrm{n}^{\circ}$. 2, de 11 de setembro de 2001. Institui Diretrizes Nacionais para a Educação Especial na Educação Básica. Diário Oficial da União, Brasília, DF, 14 set. 2001. Disponível em:

$<$ http://portal.mec.gov.br/arquivos/pdf/resolucao2.pdf/>. Acesso em: jul. 2020.

BRASIL. Ministério da Educação/Secretaria de Educação Especial. Classe hospitalar e atendimento pedagógico domiciliar: estratégias e orientações. Brasília: MEC/ SEESP, 2002.

CAIADO, K. R. M. Aluno deficiente visual na escola: lembranças e depoimentos. Campinas-SP: Ed. Autores Associados/PUC, 2003.

CECCIM, R. B. Classe Hospitalar: encontros da educação e da saúde no ambiente hospitalar. Revista Pedagógica Pátio, Porto Alegre, n. 10, p. 41-44, ago./out. 1999.

FONSECA, E. S. Classe Hospitalar: ação sistemática na atenção as necessidades pedagógicas - educacionais de crianças e adolescentes hospitalizados. Temas sobre Desenvolvimento, RJ, v. 8, n. 44, p. 32-37, 1999.

FONTES, R. S. A classe hospitalar e a inclusão da criança enferma na sala de aula regular. Revista Brasileira Educação Especial, Marília-SP, v. 8, n. 1, p. 45-54, 2002.

FONTES, R. S. A reinvenção da escola a partir de uma experiência instituinte em hospital. Educação e pesquisa, São Paulo, v. 30, n. 2, p. 271-282, 2004. 
GONZÁLEZ, E.; GONZÁLEZ, C. Classes hospitalares. In: GONZÁLEZ, E. et al. Necessidades educacionais específicas. Porto Alegre: Artmed, 2007. p. 344-369.

HARE, N.; DURHAM, S.; GREEN, E. Paralisias Cerebrais e Distúrbios de Aprendizado Motor. In: STOKES, M. Neurologia para Fisioterapeutas. São Paulo: Editora Premier, 2000. p. 255-269.

LAKATOS, E. M. Fundamentos de metodologia científica. São Paulo: Atlas, 2003.

MAIA-VASCONCELOS, S. F. Penser l'école et la construction des savoirs. Berlim: Editions Universitaires Européennes, 2010. v. 01.454 p.

MATOS, E. L. M.; MUGIATTI, M. T. de F. Pedagogia hospitalar: a humanização integrando educação e saúde. 4. ed. Petrópolis, RJ: Vozes, 2009.

ORTIZ, L. C. M.; FREITAS, S. N. Classe hospitalar: caminhos pedagógicos entre saúde e educação. Santa Maria-RS: UFSM, 2005.

SANDRONI, G. A. Classe hospitalar: um recurso a mais para a inclusão educacional de crianças jovens. Cadernos da Pedagogia, São Paulo, v. 2, n. 3, p. 1-13, 2008.

ZOMBINI, E.V.; BOGUS, C. M; PEREIRA, I. M.T. B.; PELICIONI, M. C. F. Classe hospitalar: a articulação da saúde e educação como expressão da política de humanização do SUS. Trab. educ. saúde, Rio de Janeiro, v. 10, n. 1, p. 71-86, mar./jun. 2012.

Recebido em abril de 2020. Aprovado em dezembro de 2020. 